\title{
De la luz de Roma al oro de Florencia. Luz y legitimación histórica en los humanistas italianos'
}

\author{
From Rome's Light to Florence's Gold. \\ Light and Historical Legitimacy in the Italian Humanists
}

\author{
GINÉS TORRES SALINAS \\ Universidad de Granada \\ España \\ ginestorres@ugr.es
}

Resumen. Durante el Renacimiento, desde sus inicios hasta su consolidación, los humanistas utilizaron la contraposición entre luz y oscuridad para legitimar, frente a la medieval, su nueva visión del mundo. En el presente artículo analizaremos el significado concreto con que se dota a la luz en dicha contraposición, así como las diferentes modulaciones que adquiere, dentro de lo que hemos llamado la Edad de la luz.

Palabras clave: luz; oscuridad; Renacimiento; humanistas; Edad de Oro.
Abstract. In Renaissance, from its beginning to its consolidation, humanists used the light/darkness opposition to legitimate, in front of the medieval one, their new world vision. In this paper we'll analyze the specific meaning with light is provided with in that opposition, as well as the different modulations that this light acquires, in what we have named the Light's Age.

Keywords: light; darkness; Renaissance; humanists; Golden Age.

\footnotetext{
I Para citar este artículo; Torres Salinas, Ginés (20I3). De la luz de Roma al oro de Florencia. Luz y legitimación histórica en los humanistas italianos. Alabe 7. [www.revistaalabe.com] (Recibido o6-O2-2OI3; aceptado I5-O4-2OI3)
} 


\section{LA EDAD DE LA LUZ}

Nada más alejado de nuestra intención que añadir otro ladrillo más al muro del "círculo vicioso" que ya en r932 detectara Cantimori (I97I: 4I5) en los casi innumerables intentos de dejar vista para sentencia una definición tajante e inamovible del concepto de Renacimiento. ¿Qué sentido tiene entonces aplicar o acuñar un concepto como el de Edad de la luz y cómo se relaciona con el de Renacimiento? El término no pretende discutir ni sustituir al de Renacimiento, sino al contrario, nace de una intención globalizadora, que no se preocupará de ponerle coto desde fuera a la vasta extensión del terreno historiográfico de los estudios renacentistas, sino que se constituirá en una especie de camino, de guía, por el que transitar dicho terreno e intentar comprender algunas de sus claves, a partir de un eje muy concreto que, a la vez, se despliega en numerosas direcciones: el de la luz.

Así, con Edad de la luz nos referimos a una suerte de clima intelectual en el que, debido a las necesidades de legitimación ideológica de la naciente burguesía (Rodríguez, I990: 59-III), la luz no solo va a cambiar de significado en tanto que cambiará la manera de leer el mundo, y con el todos sus signos, sino que, además, como resultado de ese cambio, la propia luz se convertirá en una herramienta, en un instrumento de trabajo al servicio de los cambios de paradigma que aparecerán en esta época en las artes plásticas, en la arquitectura, en los nuevos descubrimientos astronómicos, en la lectura que se hará de determinadas referencias mitológicas de la antigüedad clásica o, como es el caso del presente artículo, en la concepción histórica de su propio tiempo.

\section{PETRARCA: LA PRIMERA LUZ}

La crítica historiográfica, desde la aparición en 1860 de la piedra angular de los estudios modernos sobre el Renacimiento, La cultura del Renacimiento en Italia, escrita por Jacob Burckhardt, ha estado ocupada de manera extensísima en rebatir o reforzar la idea de una Edad Media oscura, bárbara. Frente a esta, el Renacimiento italiano se había convertido ya en un mito casi meridional del que daba cuenta el dibujo que en ${ }_{17}{ }_{7} 7$ Tischbein el Joven hizo a un "heliotrópico Goethe llenándose de la luz romana que bañaba de sol su habitación en la Vía del Corso" o el Aby Warburg que, en 1929, poco antes de morir, "hacía resumen de su vida al decir que el era como un "heliotropo" que se había vuelto hacia el pasado de las tierras de Italia buscando la cálida luz del sol” (Bouza, 2004: 7). En contraste con estas dos imágenes, Theodore Mommsen explica cómo, aún en su edición de г9п, la Encyclopaedia Britannica, al ocuparse de la Edad Media, utilizaba para referirse a ella la expresión "Dark Age” (1942: 226). Que la edición más emblemática de la Britannica, escrita por las que se suponían algunas de las plumas más rigurosas de la 
época, reproduzca esta idea de la Edad Media como una época oscura, nos muestra hasta qué punto -en intensidad y en extensión temporal- caló la idea de que el enfrentamiento entre los dos periodos - no nos interesa ahora discutir si existió o no un enfrentamiento efectivo, ni cuál sea la dimensión de la fractura- podía cifrarse en la oposición entre una luz de cuyo mito participaban, siglos después Goethe y Warburg, y la oscuridad.

Lo que trataremos de hacer es delimitar la aparición y los motivos que condujeron al nacimiento de ese mito del que participaban Goethe y Warburg, y que no es sino una extensión de la conciencia que el hombre del Renacimiento tendrá de estar viviendo un tiempo nuevo y distinto al medieval. Dentro de ese debate, el hilo de la luz será uno de los más importantes sostenes en que los primeros humanistas tratarán de legitimar sus propias posturas.

Existe un más que amplio consenso en considerar a Petrarca, al menos a nivel simbólico, como el primero de los humanistas o, si se quiere, el primero de los puntales que tuvo el Renacimiento a la hora de reconocerse a sí mismo como un nuevo periodo en la historia del hombre. Fue el propio Mommsen el primero que se ocupó -en un artículo seminal, seguido y también discutido- de explicar cómo la concepción petrarquesca de la historia fue la primera que identificó el enfrentamiento de su propio tiempo con un periodo inmediatamente anterior, a través de los símbolos de la luz y la oscuridad. En el texto de Mommsen encontramos un revelador pasaje sobre el uso que Petrarca hará de la luz en sus formulaciones sobre la historia. Se trata de un pasaje del Africa, IX, 452-457 y dice así:

[...] a ti, si -como espera y desea mi alma- me sobrevives muchos años, te aguardan quizá tiempos mejores; este sopor de olvido no ha de durar eternamente. Disipadas las tinieblas, nuestros nietos caminarán de nuevo en la pura claridad del pasado (en Panofsky, 1975: 42-43).

El fragmento corresponde a la dedicatoria que Petrarca dirige, en el canto IX del poema, al Rey de Nápoles, Roberto de Anjou. Petrarca formula esta concepción temporal desde un momento en el que aún no están disipadas las tinieblas, con un tono que mezcla la esperanza y el desengaño de quien no podrá ver esos "quizá tiempos mejores". Lo que nos importa, sin embargo, es que ya se delinea claramente la concepción de dos periodos históricos separados de manera radical, tal como manifiesta la contraposición entre unas tinieblas que deberían ser disipadas, un sopor (en el original latino la referencia es al Leteo) que tampoco se presupone eterno, y una "pura claridad" asociada a un "pasado" que, en el fragmento, Petrarca no define.

A poco que, sin embargo, se recorra su obra, se advertirá que ese "pasado" no es otro que el del esplendor perdido del antiguo Imperio Romano, cuyo canto elogioso era para Petrarca la almendra misma de la historia, en líneas que funcionan casi a modo de manifiesto: “¿Qué otra cosa es la historia, sino el elogio de Roma?” (en Mommsen, 1942: 237). No se agazapa tras esta postura de recuperación de la antigüedad la mera nostalgia de la época imperial, sino todo un programa ideológico. 
El interés por el mundo clásico no es, evidentemente, nuevo ni exclusivo de la visión renacentista del mundo: que los autores clásicos fueron leídos y citados con profusión durante el medievo es una obviedad que queda fuera de toda discusión. Más interesante será definir y comprender la manera en que autores como Petrarca volverán a ellos, qué actitud desarrollarán hacia la Antigüedad clásica, incluso como modelo de vida. Juan Carlos Rodríguez (I990: I43-I46) ha explicado cómo esta particular vuelta al clasicismo que arrancaría -al menos simbólicamente, como hemos explicado- de Petrarca y se consolidaría durante el Renacimiento se debe a que "la ideología burguesa desde su primera fase "humanista italiana" utilizó una especial imagen de "lo griego" (o del mundo helenoromano en general) forjada en las necesidades de su lucha contra el escolasticismo feudal" (p. I43).

La mirada vuelta hacia la Antigüedad clásica -romana en el caso de Petrarcay, posteriormente, en el círculo neoplatónico florentino, hacia el mundo griego representado por Platón- se convertirá por tanto en un ejercicio de legitimación por parte de la naciente burguesía de las ciudades estado, frente al mundo feudal del periodo inmediatamente anterior. Este ejercicio legitimador se traducirá en una lucha por la apropiación y la interpretación de los símbolos, en cuyo seno la luz será dotada de un contenido concreto y puesta al servicio, en tanto que símbolo, de una serie de propósitos determinados.

Wallace Ferguson, en The Renaissance in historical thought (I948), detecta, a partir de un primer hito como es la Chronica de la ciudad de Florencia que escribe Giovanni Villani en la primera mitad del siglo XIV, un cambio en la concepción de la historia (I948: 6-7). Esta pasa de ser escrita desde un punto de vista universal (sub specie aeternitais), en el que el referente estructurador de la misma son los seis días de la creación o las cuatro monarquías de la profecía bíblica de Daniel, a una historia, como es el caso de la Chronica de Villani, que aunque sin acabar de despegarse de un sentido teológico -y, añadimos, teleológico- de la historia, sí que comienza a presentar rasgos de un estudio independiente sobre la vida económica y política de la Florencia del momento. Hans Baron (I993: 44-64), estudiando en estricto la sociedad florentina, recoge el guante de Ferguson y coloca en la Historiarum florentini populi, Libri XII, de Leonardo Bruni, el momento en que "los fenómenos fundamentales de la vida entre los Estados, previamente subordinada a la teología histórica del Sacrum Imperium, pueden ser considerados de forma más inteligible, dándoles una explicación causal” (p. 46). Bouwsma (200I: 77-95), aunque centrando su foco temporal ya en pleno siglo XVI, coincide en la aparición con el Renacimiento de un tiempo "secular", distinto del "tiempo sagrado" (p. 77), coincidente "con el surgimiento de las ciudades, en las que el tiempo se medía y valoraba cada vez más para infinidad de usos humanos” (p. 78), de tal manera que la reflexión histórica, en sintonía con lo que señalaba Baron, tenía un marcado "interés por hacer inteligible la cadena de sucesos" (p. 8I). Dejando a un lado los matices cronológicos que llevan a fijar el punto de partida de la nueva concepción de la historia antes o después, lo que merece la pena recalcar es la idea de que ese cambio en la concepción de la historia es efectivo y estudiar, en consecuencia, sus efectos sobre la serie terminológica luz/oscuridad. 
Podemos así insertar a Petrarca en esta nueva corriente de interpretación de la historia, conviniendo con el propio Ferguson en que "Petrarch set the tone for the humanist's secular interpretation of history" (p. 8). Esta secularización supondrá que "desaparecida la Escritura como único sostén del texto" (Rodríguez, 2OoI: 27), "aparecen también los signos literales sustituyendo a las signaturas divinas" (Rodríguez, 20o8: I66). El juego de símbolos luz/tinieblas o luz/oscuridad que caracteriza la mirada que Petrarca vuelve hacia esa Roma imperial cuyo elogio será la historia, estará también al servicio de ese cambio y él mismo lo sufrirá.

Efectivamente, la metáfora de la existencia de una edad oscura previa a la llegada de la luz no la inventan ni Petrarca, ni los humanistas. Fue utilizado ya por la tradición cristiana, a partir de la estructura histórica que explicó Eric Auerbach en Mímesis, donde sostiene que en la Edad Media la concepción de la historia se establece en torno a "La meta de la historia de la salvación [que] no es tan solo una esperanza segura para el futuro, sino que se halla cumplida en Dios desde siempre, y prefigurada en cuanto a los hombres de la misma manera que Cristo se halla prefigurado en Adán” (I975: I85), esto es, construyendo el devenir temporal en torno al eje central que supone la figura de Cristo. Cada signo del mundo se leerá desde ahí, y no será de extrañar por ello que la dialéctica entre luz y oscuridad se formule, bajo estas premisas, a partir del episodio central del cristianismo: la venida al mundo de Cristo (Mommsen, I942: 227), (Ferguson, I948: 8). La llegada del Mesías sería leída e interpretada, dentro de nuestro campo semántico luz/oscuridad, como la caída de un rayo luminoso que parte y divide en dos la historia. La luz de la venida de Cristo daría lugar a la división entre "historiae antiquae e historiae novae", y la historia debería interpretarse en un "desarrollo continuo como un progreso ininterrumpido desde las tinieblas paganas hasta la luz de Cristo" (Panofsky, I975: 42).

En Petrarca se puede percibir la ejecución de este paso de la luz de Cristo a la luz Romana, de la concepción de la edad pagana como una edad oscura a la idea de que con la pérdida de esa Roma pagana comenzó una era de tinieblas. Un balanceo de percepciones que ya Ferguson advirtió en la Chronica de Villani, y en el que Petrarca se erige como simbólica bisagra.

En el De ignorantia, escrito en I37, hay un pasaje en que Petrarca entona su lamento por Cicerón, muerto apenas cuarenta años antes del nacimiento de Cristo. Aquí, su discurso se tiñe aún de esta interpretación cristológica de la luz:

¡Cuánto he compadecido su suerte, al leer sus obras! ¡Lamento tanto en mi fuero interno que ese hombre no haya conocido al verdadero Dios! La muerte cerró sus ojos pocos años antes del nacimiento de Cristo. ¡Cuán próximos estaban, ay, el fin de la tenebrosa noche del error y el comienzo de la era de la verdad! Era inminente el alba de la luz verdadera y el sol de la justicia (I978: 182). 
Si regresamos ahora a la dedicatoria del África que citamos al principio veremos que, frente a la noción del tiempo precristiano como un tiempo de oscuridad que le tocó vivir a Cicerón, en la dedicatoria al rey francés hay ya una concepción nueva y distinta del periodo luminoso. Petrarca, efectivamente, nos ha servido de bisagra entre una y otra concepción, superando esa primera postura, como nos demostrará algún ejemplo más de lo que Miguel Ángel Granada ha llamado una "concepción invertida de la historia" (Granada, 2009: I7).

Petrarca decide dedicar sus esfuerzos como historiador -cifrados en el conjunto de biografías del incompleto De Viris Illustribus- a un límite temporal muy concreto: el de una Roma imperial presentada como luminosa, ajena a las tinieblas. Una concepción de la historia que quedaría cifrada en aquel fragmento de la Apología contra cuiusdam anonymi Galli calumnia, en el que sostiene que "Entre el error brillaban hombres de genio, y no menos aguda era su vista, aunque estuvieran rodeados de oscuridad y densa niebla" (en Mommsen, r942: 225) ${ }^{2}$; o en una epístola escrita por Petrarca a su hermano Gerardo, en la que el saludo que le dirige después de dos años sin hablar lleva inscrito la luz, transformada, como hemos visto, no solo en un símbolo más o menos retórico, sino en todo un proyecto histórico que Petrarca transforma en su propio proyecto de vida: "Es mi deseo, hermano más que la luz por mí querido, poner fin a este prolongado silencio” (Petrarca, 1978: 283).

\section{PETRARCA Y COLA DI RIENZO: LA LUZ DE ROMA}

Petrarca se erige así como el padre de la nueva concepción luminosa de la historia, a partir de un programa ideológico perfectamente definido. Sin embargo, antes de continuar con el desarrollo del motivo luminoso en la generación de humanistas que le seguirá, será necesario refinar un poco más la revuelta petrarquesca contra las tinieblas medievales.

Eugenio Garin, en un pequeño ensayo titulado significativamente Edades oscuras y Renacimiento: un problema de límites, alerta sobre el riesgo de olvidar los matices que diferencian "formulaciones de orden genérico" del tipo de la que nos ocupa aquí:

Ahora es el momento de avanzar una importante advertencia: en los grandes periodos, en los "tiempos largos”, es plenamente lícita una aproximación tan indiscriminada como sugerente a los textos de los siglos XIV, XV, XVI y, ¿por qué no?, también a los del XVII y XVIII. Por el contrario, si nos interesamos por los "tiempos cortos", cuando lo que se persigue no es ya detectar "formas" recurrentes, sino etapas reales

\footnotetext{
${ }^{2}$ La traducción es nuestra.
} 
de las transformaciones históricas de la cultura, se imponen delimitaciones mucho más delicadas y sutiles. En consecuencia, si bien las formulaciones de orden genérico no se diferencian con nitidez, hasta el punto de parecer prácticamente idénticas, metáforas como las de la luz y las tinieblas o el renacimiento y la muerte se "alejan" extraordinariamente unas de otras según sean los tiempos y los usos (I981: 47-48).

A partir de esta distinción entre ciclos largos y ciclos cortos, Garin sugiere que el estudio de nuestra serie terminológica luz/oscuridad/tinieblas en el periodo al que nos estamos dedicando solo tendrá sentido y será fructífero si somos capaces de captar los matices y vaivenes que va adquiriendo el término a lo largo del periodo que conforma esta Edad de la luz. Deberíamos tener la precaución, advierte Garin, de no mezclar en un todo homogéneo las diversas concepciones histórico luminosas de Petrarca, Salutati, Bruni y Vasari (p. 50).

Será necesario, así, tomar posición ante las diferentes formas de interpretar la postura y la mirada a la Antigüedad tanto de Petrarca como del movimiento humanista en general. Coincidiendo con Kristeller (I993: $3^{8-} 5^{\mathrm{I}}$ ) en que uno de los sostenes del humanismo será el interés por un proyecto que se interesa por la retórica, por la filología, no estamos tan de acuerdo, sin embargo, en su intento de circunscribir la actividad de los humanistas a un estrecho campo de estudio que lo alejaría de ser "una tendencia o sistema filosófico", limitándolo solo a un "programa cultural y educativo" (p. 40), que en el caso paradigmático de Petrarca "puede resumirse en la fórmula que usa alguna vez en el tratado De su ignorancia: sabiduría platónica, dogma cristiano, elocuencia ciceroniana" (Kristeller, I97O: 33). Reconociendo que gran parte de los ataques de Petrarca contra la escolástica tienen un trasfondo retórico o literario, si recordamos los pasajes que acabamos de analizar, estaremos de acuerdo en que hay algo más que preocupación retórica o educativa en su actitud. Nos situamos así en un punto vecino al de la apertura de campo de Francisco Rico, cuando sostiene que "la idea de que los studia humanitatis así concebidos, haciendo renacer la Antigüedad, lograrán alumbrar una nueva civilización” (I993: I8); o al de Eugenio Garin, cuando escribe que

Ciertamente, el Renacimiento fue, ante todo, un gran movimiento cultural que remodeló los espíritus sin agotarse en un hecho puramente literario o gramatical. Si bien, en efecto, los humanistas hablan mucho de libros, de bibliotecas, de textos y de vocablos, hemos de tener en cuenta que las letras humanas no son exaltadas por sí mismas, sino por el hecho de ser formadoras en el hombre de su más digna humanidad (I986: I5).

El origen de la serie terminológica, siguiendo a Garin, es concreto y delimitado. Se presenta en el ámbito de la batalla contra la ignorancia de unas universidades que, en el siglo XII, han abandonado el fervor por los clásicos -y todo lo que esa enseñanza basada en ellas pudiera tener de humanitas- en favor de los lógicos (Garin r98ı: 54-9). Habrá que decir, sin embargo, que esa batalla iniciada por Petrarca contra la ignorancia bárbara, o, 
directamente, contra la oscuridad, es la parte visible de un iceberg en cuya base hay algo más sólido y profundo: “El Renacimiento, nacido con Cola di Rienzo y con Petrarca como un movimiento de insurrección nacional, como una lucha contra los “bárbaros”, cultural a la vez que política" (Garin, I986: ı6), esto es, ideológica.

Estamos ya en condiciones de afirmar que el uso que Petrarca hace del símbolo de la luz desde una perspectiva historiográfica queda perfectamente delimitado: la luz enlaza con una civilización romana que para Petrarca se va a convertir en un modelo, no solo literario, sino también político. Este nuevo proyecto tendrá su principal representante en la figura de Cola di Rienzo, quien en I343 escribía:

Levántese el pueblo romano de su postración, ascendiendo al trono de la majestad de antaño, quítese la lúgubre vestimenta de la viudedad [...] Ahora, en efecto, que los cielos se han abierto y que, nacida de la gloria de Dios Padre, la luz de Cristo, difundiendo el esplendor del Espíritu Santo, a vosotros que vivís en las sombras tenebrosas de la muerte os ha preparado la gracia de una inesperada y admirable claridad (en Garin, I986: 28).

La aparición de "la luz de Cristo" debemos tomarla con cuidado porque no se trata de la concepción figural del símbolo propia de la Edad Media, sino del uso matizado e inteligente del símbolo por parte de Cola di Rienzo, dirigido hacia sus propios intereses. Cola, que al igual que Petrarca sigue conservando ciertos "escrúpulos religiosos" dentro del proceso de secularización (Kristeller, ı970: 30), baña con la luz de Cristo su propio proyecto político. La luz no aparece porque nazca Cristo y con él la historia se haya partido en dos, sino porque justo en ese I343 Cola di Rienzo comenzará, gracias a su ascendente sobre el Papa Clemente VI, a ver muy cerca la posibilidad de hacer real su proyecto político. La "inesperada y admirable claridad” que disiparía "las sombras tenebrosas de la muerte" no es la venida de Cristo en sí, sino el posible cambio de sede papal de Avignon a Roma, con el que se acabaría la postración del pueblo romano. La escenificación del cambio se remata con una imagen envidiable, por sencilla: la de "la lúgubre vestimenta de la viudedad”. No es solo que el pueblo romano esté viudo, esto es, con la verdadera sede papal muerta y sin nadie que la ocupe, sino que esa situación, la figuración contraria a la luz, Cola la extiende hasta el símbolo cotidiano de la vestimenta: lúgubre, tenebrosa, negra.

\section{LOS HUMANISTAS: HIJOS DE LA LUZ}

Petrarca y Cola di Rienzo pusieron las bases de una concepción de la historia que encontró en la contraposición entre las luces y las tinieblas expresión privilegiada. Con 
las cenizas de Cola di Rienzo flotando sobre el Tíber, después de su ejecución, la imagen sufrirá un desplazamiento de foco. No quiere decir, por supuesto, que se pierda el interés por la historiografía, como demuestra Flavio Biondo, quien en I474 escribe en su Italia Ilustrada que

[...] he querido intentar, con el conocimiento que he tenido de los acontecimientos de Italia, dar noticia de los nombres de los lugares y los pueblos antiguos, dar autoridad a los nuevos, y a los desaparecidos, una vida en el recuerdo; y, finalmente, iluminar la oscuridad de las vicisitudes itálicas (en Garin, I986: 46).

Aquí, los antiguos se convierten en legitimadores de los nuevos y la historiografía en un método iluminador de las dificultades que atravesaban los pueblos itálicos. Como vemos en esta declaración de intenciones, comienzan ya a matizarse las propuestas políticas concretas de Cola di Rienzo.

Francisco Rico ${ }^{3}$ y Eugenio Garin ${ }^{4}$ coinciden en que existe no poco de mito en la construcción de la visión renacentista a la Antigüedad clásica. Mito perfectamente comprensible si pensamos que esa vuelta a la Antigüedad busca no tanto un sentido arqueológico -en el sentido que hoy podemos dar a la arqueología-, sino la construcción de un ente histórico en el que la naciente burguesía pudiera encontrar un espejo que le interesaba fuera más legitimador que verosímil.

Se comenzará a construir una visión distinta de ese mito de la Antigüedad, en la que los humanistas no estarán tan interesados en concebir la contraposición entre la luz y la oscuridad como un término historiográfico que entendiera la renovación en el sentido estrictamente político del Cola di Rienzo que pretende devolver el papado a Roma, como en aplicar la serie a la renovación artística, al papel de sabios ilustres -muchos de ellos, aunque muy cercanos en el tiempo (Petrarca, Dante), ya también incorporados al mito-, encargados de devolver el esplendor cívico por la vía del esplendor temporal.

Boccaccio, contemporáneo y buen amigo de Petrarca, se inclinará hacia este matiz. Lo hará con dos ejemplos bien conocidos y significativos: Dante y Giotto. No nos interesa discutir si estos merecerían o no aducirse como ejemplos de esa renovación, esto es, situarlos en la órbita del Renacimiento o dejarlos aún dentro de los límites medievales, sino mostrar que para Boccaccio, ya se habían convertido en abanderados de la renovación.

\footnotetext{
3 "Pero tampoco cabe desdeñar esas ideas y esas explicaciones históricas como pura mitología, porque a veces son los mitos quienes crean las realidades" (I993: 5I).

4 "Cuando la inspiración religiosa y un fuerte espíritu de recuperación nacional entran en contacto con una reivindicación de la obra de los clásicos, la polémica cultural, todo hay que decirlo, de orígenes bastante limitados, se transforma en un mito de excepcional fuerza" (I98I: 63).
} 
En su Vita di Dante Aliguieri, de I357, Boccaccio se refiere así al momento en que la madre de Dante dio a luz al poeta: "partorì la donna questa futura chiarezza della nostra città [...] questi fu quel Dante, il qual primo doveva al ritorno delle Muse, sbandite d'Italia, aprir la via. Per costui la chiarezza del fiorentino idioma è dimostrata" (Boccaccio, I830: 6)5. Comparado el texto de Boccaccio con los testimonios de Petrarca y de Cola di Rienzo, nos daremos cuenta de que aparece algo nuevo: el énfasis en que será un personaje en concreto el que traiga la "chiarezza" a la ciudad de Florencia. No se trata ya de un proyecto colectivo -la restauración de la luz romana-, se trata de la fuerza de una poderosa individualidad -si queremos, un miembro de la colectividad de la "república de las letras" humanista (Burke, 2000: 82), (Bouwsma, 200I: 16-2I)- fruto de uno de los acontecimientos centrales del Renacimiento: la aparición del sujeto moderno ${ }^{6}$, encargado de portar una "chiarezza", una gloria, un estatuto de nobiltà, que será devuelta a la ciudad de Florencia y, a la vez, dará carta de naturaleza al idioma toscano.

Individualidad y restitución cultural serán las dos coordenadas que orienten el elogio que Boccacio hará de Giotto en el Decamerón. En la quinta novela del sexto día, leemos:

E per ciò, avendo egli quella arte ritornata in luce, che molti secoli sotto gli error d'alcuni, che più a dilettar gli occhi degl'ignoranti che a compiacere allo 'ntelleto de'savi dipigneano, era stata sepulta, méritamente una delle luci della fiorentina gloria dir si puote; e tanto più, quanto con maggiore umiltà, maestro degli altri in ciò vivendo, quella acquistò, sempre rifiutando d'esser chiamato maestro. Il quale titolo rifiutato da lui tanto più in lui risplendeva (Boccaccio, 1952: 440).

Boccaccio esgrime de nuevo la idea de devolver el arte a la luz, después de haber estado durante muchos siglos en la oscuridad del error; y otra vez nos encontramos con la luz individual de un pintor que, gracias al dominio de su arte, se ha convertido en "luz de la gloria florentina" y ha meritado el poder ser llamado "maestro", título que, escribe explícitamente Boccaccio, resplandecía poderosamente en su persona, modulando así el tópico que asociaba la luz al intelecto. Se percibe ya un cambio en la tonalidad de la luz como término histórico, en su matiz, con respecto a los textos de Petrarcay Cola di Rienzo.

Esta conversión en mito alcanzará velozmente al propio Petrarca, de quien muy pronto se comenzó a escribir en términos semejantes a los de Dante. Tanto es así que Coluccio Salutati, en una carta de I395 (Salutati, I89I: 79-85), se refiere a una "lumina florentina" que hizo emerger los estudios literarios, en la que coincidirían Dante, Petrarca e incluso Boccaccio.

\footnotetext{
5 Sin olvidar que, como bien señala Robert Black (2006: 305-306), ya Guido de Pisa en un comentario a la Commedia, escrito hacia I330, había lanzado la idea de un Dante trayendo la poesía a la luz después de haber estado muerta: "Ipse enim mortuam poesiam de tenebris reduxit ad lucem".

${ }^{6}$ Cfr. Rodríguez (I99O: I2O-I2I; 2OOI: 27-33;45-46) o Kristeller (I97O: 27-28), donde se hace referencia a la carta de Petrarca a Dionisio da Burgo San Sepolcro (2000: 25-35), en que relata la subida al Mont Ventoux, como ejemplo de esa reflexión interior, volcada hacia el propio sujeto.
} 
Cuando Leonardo Bruni escriba en I 434 su Vita del Petrarca, hablará, efectivamente, de la libertad que han recuperado los pueblos itálicos, pero en seguida apuntará que "Francesco Petrarca fue el primero [que supo de estilo literario, junto a Dante], quien tuvo tanta gracia de ingenio que reconoció y volvió a la luz del día la antigua elegancia del estilo extinto y perdido" (en Garin, I986: 55). Dentro de este mismo clima luminoso, la llegada de Manuel Chrysoloras a Florencia como profesor de griego es saludada por el erudito ferrarés Guarino Veronese como la recuperación por parte de las letras italianas de su "pristinum fulgorem" (Guarino Veronese, I9I5: 588). La base de la renovación se hace libresca y encuentra así en los humanistas una perfecta legitimación de su propia ocupación personal, de su pasión de vida literaria, del mundo nuevo, en definitiva, que está surgiendo.

Lorenzo Valla, en su muy humanista defensa del uso de la lengua latina, busca un punto de luminosa concordia con las demás lenguas vulgares. En el prólogo al primer libro de sus Elegantiae (finalizadas en I440) leemos una comparación que muy pronto adquirirá un denso significado: “Así como una gema no afea el anillo de oro en que está engastada, sino que lo adorna, de igual modo nuestra lengua aporta esplendor a las lenguas vernáculas, no se lo resta" (Valla, 2000: 77). Algo más adelante, en el mismo prólogo, Valla se lamenta por el triste destino de la latinidad, lo que achaca a que "los restantes lectores no han entendido ni entienden los libros de la Antigüedad, como si tras la caída del imperio romano ya no fuera apropiado ni hablar ni saber latín, dejando que el descuido y la herrumbre apaguen aquel esplendor de la latinidad" (p. 79).

Francisco Rico (I993: I7-I8) recupera la figura de un humanista portugués, Pedro Nunes, cosmógrafo atento a los problemas que se derivaban de la navegación. Cuenta Rico que Nunes, mientras trabajaba en su Libro de álgebra, compuso este epigrama, donde alaba las bondades de la gramática, de nuevo a través de la luz:

Tú que arrostras sin miedo las fatigas,

aplícate dispuesto a la gramática,

madre que nutre todos los saberes,

y si logras la dicha de alcanzarla,

por entre las marañas de las ciencias,

tendrás al fin la luz a que aspirabas.

La luz, el resplandor, han quedado circunscritos al ámbito literario y gramatical. Creemos que el final de Cola de Rienzo sigue vivo en la memoria de los humanistas, de manera que los modelos a adoptar ahora serán, sobre todo dos: Dante y Petrarca. La serie sigue encontrando acomodo en el recuerdo por la Antigüedad romana, transformado ahora en una obsesión por fijar por escrito la admiración por una primera generación de autores que han devuelto a la luz la elegancia, el estilo, el buen escribir, el saber, convertidos en las armas contra las que combatir un horizonte de oscuridad medieval que aún, en las primeras generaciones de humanistas, se siente cercano. 
Esta idea se extiende por todo el periodo. La recoge, por ejemplo, Lapo da Castilglionchio, quien escribe al Cardenal Orsini las siguientes palabras:

Tú has salvado del olvido y del silencio a muchísimos sabios, volviendo a hallar las obras que antes permanecían en la ignorancia. En efecto, para no mencionar a los muchos ya conocidos cuyas obras en gran número has vertido al latín, has devuelto a la luz a muchísimos de los que no sabíamos ni siquiera el nombre (en Garin, r986: 44).

A la devolución a la luz -sintagma cuyo uso solidifica en casi todos estos testimonios- se le apareja aquí un matiz importante, como es el de la traducción, convertida en un recurso más para combatir esa ignorancia que, en tantas ocasiones, se identifica con las tinieblas o la oscuridad.

En Poggio Bracciolini, y en la leyenda que generó con su muerte, hallamos la cristalización perfecta de esta nueva postura. En sus Historiae de Varietate Fortunae, recoge el testimonio de uno de sus viajes a Roma. Cuando contempla las ruinas de la ciudad antigua, le invade la nostalgia por un imperio romano cuya capital, "que fue floreciente y admirable para todo el mundo, está hasta tal punto desolada, arruinada y cambiada respecto de lo que fue su primitivo esplendor" (en Garin, I986: 39). El recuerdo por la Roma no vivida y esplendorosa sigue latente en Bracciolini, quien trata de restituir su herencia mediante la búsqueda incesante de códices y manuscritos. Entre otros, recupera, el De rerum natura, de Lucrecio, o los libros de arquitectura de Vitrubio. En De Rerum Italicorum Scriptores cuenta cómo en I4I6, en mitad del Concilio de Constanza, aprovechó para visitar el cercano monasterio de Saint Gall, en la actual Suiza. Revolviendo y disfrutando entre los manuscritos del monasterio, descubrió un ejemplar completo -con todo lo que ello supuso de simbólico y representativo- de las Instituciones oratorias de Quintiliano.

La descripción es un alegato, a la vez hermoso y conmovedor, en pos de los libros y el saber: "Aquellos libros, efectivamente, estaban en la biblioteca, y no como lo exigía su dignidad, sino como en una tristísima y oscura cárcel, en el fondo de una torre en la cual no se habría encarcelado ni siquiera a los condenados a muerte" (en Garin, I986: $42^{-}$ 3). Seguramente la escena tiene un punto de exageración y no podemos estar seguros de hasta qué punto los libros se encontraran realmente en aquellas penosas circunstancias. Pero lo que no podemos dejar pasar es la intención de Bracciolini de mostrarnos la necesidad de que los clásicos se vivificaran, salieran de una cárcel en la que se encontraban rodeados de una oscuridad que les arrebataba su dignidad. El movimiento humanista dotó a las obras de los clásicos, en su actualizado interés por ellos, de un estatuto similar al que se está dando al propio ser humano, una dignitas que, para poder irradiar su luz, necesita ser sacada de la oscuridad carcelaria de un lugar físico y real -en tanto que muchos de esos códices estaban literalmente escondidos-, pero también del lugar simbólico que sería la oscuridad de su desconocimiento, del dejarlos de lado, del no aplicarlos como guía moral de la propia vida. 
Cristóforo Landino, perteneciente a una generación posterior de humanistas, dedica un canto fúnebre a Poggio, escrito en sintonía con los cánones quattrocentistas de encomio cívico. En dicho canto insiste en la idea que el mismo Bracciolini había conformado en su relato de los códices de Saint Gall. Escribe Landino que Poggio Bracciolini habría contribuido a "sacar a la luz los monumentos de los antiguos, para no dejar que tristes lugares encerrasen tantos bienes, se atrevió a desplazarse hasta los pueblos bárbaros y a buscar las ciudades escondidas en las cimas de los montes Lingonicios" (en Garin, I986: 42). El aura de leyenda, casi aventurera, es evidente y apuntala de manera muy eficaz el esfuerzo por traer a la luz a los autores antiguos. El elogio fúnebre no se detiene aquí y recurre a la mitología para ilustrar el descubrimiento del De Rerum Natura:

Y te devuelve a ti, ¡oh Lucrecio!, a la patria y a los conciudadanos después de tanto tiempo, Pólux pudo arrancar de las tinieblas del Tártaro a su hermano, cambiándose por él; Eurídice siguió las melodías de su esposo, destinada a volver de nuevo a los negros abismos; Poggio, en cambio, saca de la oscura calígine a hombres tan grandes hasta el lugar donde habrá eternamente una clara luz. Una mano bárbara había sumido en la negra noche al maestro de retórica, al poeta, al filósofo, al docto agricultor; Poggio consiguió devolverles una segunda vida, liberándolos con arte admirable de un lugar infame (en Garin, I986: 43).

Landino -que no vacila en intensificar términos que viene manejando toda la tradición humanista, contraponiendo a la "oscura calígine" una eterna y "clara luz" - introduce una variante que interpreta la mitología a partir de la serie luz/oscuridad. Poggio es comparado con Orfeo o el dióscuro Pólux, dos mitos que tienen en común el haber rescatado de la fúnebre oscuridad del Hades a sus seres queridos, sin haber podido alcanzar, sin embargo, la plenitud de sus deseos: Orfeo no pudo resistir a mirar atrás justo antes de abandonar el Hades, lo que supuso la vuelta de Eurídice "de nuevo a los negros abismos"; en cuanto a los Dióscuros, unidos por estrechísimos lazos fraternales, una versión del mito los hermana solo por vía materna, resultando Cástor mortal y Pólux inmortal: a la muerte de Cástor, Pólux le pidió a Zeus, su padre, compartir su don inmortal con su hermano, y desde entonces los dos se turnan en ocupar el Hades y el lugar correspondiente a las divinidades, de manera que la figura de Pólux se erige como aquella que rescata el alma de su hermano de la oscuridad.

Landino, al comparar estos dos mitos con la figura de Poggio, ejerce una lectura de los mismos en clave luminosa: si ellos no consiguieron devolver a la luz de manera completa a la amada o al hermano, Poggio sí que fue un héroe luminoso, capaz de devolver una "segunda vida" a aquellos -los clásicos- a quienes "una mano bárbara había sumido en la negra noche".

Paolo Cortesi escribe un De hominibus doctis, uno de esos tratados biográficos que tanta fortuna adquieren en el Renacimiento donde se recopilan las vidas de una serie de personalidades de la cultura italiana, sobre cuya importancia ya advirtió Jacob Burckhardt al escribir que 
[...] las gentes de Florencia empezarían entonces a encontrar gran placer en describirse a sí mismas, envolviéndose al hacerlo en el merecido fulgor de su gloria intelectual; quizá la cúspide de su autoconciencia la alcanzarán, por ejemplo, al explicar la supremacía artística de Toscana sobre el resto de Italia, no como obra de un talento autóctono de particular genialidad, sino como resultado de su esfuerzo y de su amor al estudio (2004: 295).

En ese tratado, Cortesi compone una encendida dedicatoria a Lorenzo de Medici, donde podemos leer:

Estoy acostumbrado, ¡oh magnífico Lorenzo!, a alabar los eminentes ingenios de nuestros contemporáneos, ya sea en las grandes empresas, ya sea, sobre todo, en esos estudios que volvieron a sacar a la luz desde las tinieblas. Cierto es que, al haberse liberado finalmente Italia de la larga opresión de los bárbaros, una muchedumbre increíble se ha dedicado al cultivo de todas las grandes artes (en Garin, I986: 80).

Traemos este pasaje de Cortesi, no como un ejemplo más de una idea que ya hemos tratado con amplitud, la de los estudios que ven la luz después de estar inmersos en las tinieblas, sino interesados en un matiz último, el de la "muchedumbre increíble" dedicada a las artes, a los estudios luminosos. En relación con el total de la población, es evidente que Cortesi exagera, pero si atendemos a su trasfondo, a lo que hay detrás, nos daremos cuenta de que la luz, en su combate contra las tinieblas, ha pasado a formar parte, a ser propiedad de una "increíble muchedumbre" de artistas y humanistas, que no dudan ya en esgrimirla como bandera.

Marsilio Ficino, en célebre y emblemática carta de I492 a Paolo di Middelburg -amigo suyo, "físico y astrónomo insigne”, que sería poco después nombrado obispo de Fossombrone y se encargaría de invitar a Copérnico a trabajar en la reforma del calendario juliano-, se refiere en parecidos y luminosos términos al fundamental regreso del platonismo que él mismo capitanea en la ciudad de Florencia

Y eso ha mostrado, casi como en Palas, en Federico, duque de Urbino, cuya virtud dio en herencia a su hijo y a su hermano. En ti, ¡oh mi Paolo!, parece haber llevado a la perfección a la astronomía, en Florencia ha vuelto a sacar a la luz del día a la sabiduría platónica (en Garin, r986: 66).

Los anhelos patrióticos de Cola di Rienzo han quedado ya disueltos en una luminosidad volcada hacia las artes y hacia los patronos que han posibilitado su desarrollo. No significa esto un retroceso en el combate que se libra contra el mundo medieval, sino un comprensible cambio en el matiz que adquiere el símbolo por parte de un colectivo, el de los escritores, los humanistas, que desarrollarán su actividad dentro de un marco 
concreto, deslindado en buena parte de los intereses de Rienzo: la consolidación de las ciudades estado. Sobre todos ellos, Florencia, que ha ido apareciendo paulatinamente en los diferentes testimonios que hemos recogido, convertida así en centro -con no pocos tintes de lugar intelectualmente mítico- del pensamiento y el arte renacentista.

\section{LA FLORENCIA DE ORO}

Marsilio Ficino iniciaba así la ya citada carta a Pablo de Middelburg:

Alabanzas a nuestro siglo, que es de oro, por sus áureos ingenios.

Marsilio Ficino a Paolo di Middelburg, físico y astrónomo insigne.

Aquello que los poetas cantaron un día sobre las cuatro edades, de plomo, de hierro, de plata y de oro, nuestro Platón, en La República, lo refiere a las cuatro naturalezas de los hombres, diciendo que en la índole de unos esta congénito el plomo, el hierro en la de otros, en otros la plata y en otros el oro, Y si, por tanto, hay una edad que hemos de llamar de oro, es sin duda la que produce en todas partes ingenios de oro. Y, que nuestro siglo sea así, nadie lo dudará si toma en consideración los admirables ingenios que en él se han hallado. Este siglo, en efecto, como áureo, ha vuelto a traer a la luz las artes liberales ya casi desaparecidas, la gramática, la poesía, la oratoria, la pintura, la escultura, la arquitectura, la música y el antiguo sonido de la lira órfica. Y eso en Florencia (en Garin, I986: 65-66).

Lo de menos, porque no suena a nuevo y ya nos hemos detenido sobre ello, es que reaparezca la idea de una vuelta a la luz de las artes liberales. Lo importante es que, desde el propio periodo, se haya desterrado ya el aura de nostalgia que envolvía muchos de los testimonios anteriores. En la carta de Ficino no existe ya el anhelo de volver a los valores de una Antigüedad que permitiría un mejor siglo ${ }^{7}$, porque este ya existe, ya se está viviendo, bajo la forma de "una edad que hemos de llamar de oro", recuperando así el mito

\footnotetext{
${ }^{7}$ No está de más reproducir la advertencia que, al respecto, hace José Lara Garrido sobre la noción de siglo: “Antes del Siglo XVIII el término siglo en la expresión Siglo de Oro tiene el alcance del saeculum clásico, esto es, no corresponde a un demarcado término cronológico sino a una indefinida aetas, cualquier época unificada por modos de vida y comportamientos" (Lara Garrido, I997: 29).
} 
clásico de una arcádica $E d a d$ de $O r o^{8}$, "que apelaba a un pasado tan distante que no había constancia de él salvo por un ideal de inocencia y simplicidad” (Bouswma, 200I: 275) que, como muy bien apunta Bouswma, era "Poco conocido durante la Edad Media" (p. 275) y que se deberá insertar dentro de un proceso histórico propio del Renacimiento, en el que "los distintos pueblos de Europa descubrían sus propios orígenes independientes de la Antigüedad” (p. 277), tal y como pretendió hacer Petrarca en su romano proyecto conjunto junto a Cola de Rienzo. En este sentido, Juan Manuel Rozas, al referirse a la noción de Siglo de Oro, apunta que

El mito de la edad dorada, o mejor, el mito de las edades, es siempre producto de una dialéctica, de una estructura, que necesita un antes y un después y un ahora para poder expresarse. El Siglo de Oro necesita, pues, para poder gestarse una sensación de decadencia, un siglo de hierro y un deseo de recuperar el esplendor en el presente. Así, desde Hesíodo al crear el tema (Rozas, 1984: 4I4).

Regresando al ejemplo concreto de la carta de Ficino, podemos adscribirla a lo que Chastel (ı982: ı9), denominó la "leyenda" medícea, a la que define como una "ficción [que] puede ser fecunda si no se toma como principio de explicación histórica y se considera como una peripecia significativa”. Más que ficción, tendría sentido hablar de construcción histórica, entendida desde un papel legitimador. A poco que se rasque sobre el término -igual da Edad o Siglo de Oro-, veremos que se inserta a la perfección dentro de la serie terminológica que venimos rastreando, consiguiendo que la expresión sirva a la legitimación política de los Medici (Gombrich: I984) o de cualquier otro gobernante, pero que, a la vez, permita que la noción pueda justificarse a sí misma, adquirir un significado concreto, casi necesario, gracias a las conexiones que el término presenta con determinados textos que circulaban en el imaginario intelectual de la época.

\footnotetext{
${ }^{8}$ La idea está ya más o menos expresada y formulada en el Hesíodo de Los trabajos y los días (I964: 4O-4I), donde leemos que "De oro fue la primera raza de hombres perecederos creada por los Inmortales [...] ellos, contentos y tranquilos, vivían de sus campos entre bienes sin tasa. [...] Una segunda raza, con mucho inferior a la primera, la de Plata, fue después creada por los moradores del Olimpo. Ni en forma ni en espíritu semejaba a la de Oro [...] Y Zeus Padre creó a su vez la tercera raza de mortales hombres, la de Bronce, en nada parecida a la de Plata". Esta concepción de la temporalidad, sin embargo, no es nueva y se remonta, como ha estudiado Harry Levin, a mucho antes, bajo distintas formas (Levin, I972: 3-3I), con un origen común, primitivo a todas ellas, que radicaría para Levin en algo parecido a un cansancio de la realidad (p. 8). Aunque en Hesíodo no aparezca la idea cronológica en sentido estricto, esta es dada a entender por la sucesión degenerativa de los hombres. Ovidio, en las Metamorfosis (I99O: IO-I2) insistirá en esta idea y ya sí que diferenciará entre las diferentes edades, cada una con sus propias características: "La edad de oro fue la creada en primer lugar, edad que sin autoridad y sin ley, por propia iniciativa, cultivaba la lealtad y el bien. No existían el castigo ni el temor [...] Una vez que, después de haber sido Saturno precipitado al Tártaro tenebroso, el mundo estuvo sometido a Júpiter, llegó la generación de plata, peor que el oro, pero más valiosa que el rubicundo bronce [...] Tras esta apareció en tercer lugar la generación de bronce, más cruel de carácter y más inclinada a las armas salvajes, pero no por eso criminal. La última es de duro hierro, de repente irrumpió toda clase de perversidades en una edad de más vil metal; huveron la honradez, la verdad, la buena fe, y en su lugar vinieron los engaños, las maquinaciones, las asechanzas, la violencia y la criminal pasión de poseer”. Así, lo que se intentaría recuperar en este ideal que va de Hesíodo a Ovidio sería “una edad de oro en la que los hombres vivirán en armonía, unidos por ideales comunes, o, cuando menos, respetando los ideales ajenos" (Blecua, 2006: 33). El gran referente renacentista será Virgilio, quien abordará la cuestión de la Edad de Oro con un matiz distinto. En la Cuarta Egloga leeremos (2003: 432): "Solo, casta Lucina, atiende amante / al niño que nos nace, a cuyo influjo, / muerta la edad de hierro, una aurea gente / en todo el mundo va a surgir: Apolo, / tu hermano reina ya". Mientras que en la Eneida, los versos quedan mas tintados, si cabe, de una considerable intención política (2003: 65I): "Y este varón, ¿lo ves?, ¿el que los dioses / tanto te han prometido, Augusto César? / Casta de un dios, al Lacio el siglo de oro / hará volver, el siglo de Saturno".
} 
E. H. Gombrich se expresa en términos cercanos a los de Chastel, al poner en relación la formulación de la Edad Dorada que aparece en Virgilio con "lo que, a falta de mejor nombre, pudiera llamarse el mito de los Médicis, que hace directamente responsables a esta familia en general y a Lorenzo en particular de esa eflorescencia mágica del espíritu humano que fue el Renacimiento" (Gombrich, I984: 69).

Evidentemente, la Edad de Oro no será solo la de Lorenzo -protagonista de la carta de Ficino-, sino la de toda la familia, desde el Giovanni di Bicci que encarga a Ghiberti las puertas del florentino baptisterio de San Giovanni o el Cosimo de Medici que convence al maestro de griego Juan Argyropoulos para ir a enseñar a Florencia ${ }^{9}$. Sin embargo, la carta de Ficino nos interesa porque condensa muy bien la imagen de la Edad de Oro que se tenía conciencia de estar viviendo, puesta al servicio, en este caso, de la poderosa figura de Lorenzo, probablemente el Medici con el que Ficino mantuvo una mejor relación a lo largo de su vida, y cuya esmerada educación, formación humanística e incluso hermosa presencia física (Marcel, 1954: 372-378), contribuirían sin duda a convertirlo en el representante por excelencia del mito familiar, según el cual bajo el mandato de los Medici florecieron con majestad las artes en la ciudad de Florencia.

Alberto Blecua recuerda que "Siglo de Oro, indica tiempo -siglo- y valor -oro-" (Blecua, I978: 3I). Si ya hemos hablado del primero de los términos, de la conciencia temporal de estar viviendo esa Edad, ese Siglo, no podemos olvidar el segundo, esto es, que sea, precisamente, de oro. El propio Marsilio Ficino en el De Vita, peculiar texto en el que da toda una serie de consejos destinados a conservar la salud, incluye el oro en muchos de los remedios que recomienda, pues, escribe:

Todos aprecian el oro por encima de cualquier cosa como la más equilibrada de todas ellas y la más inmune a la corrupción. Está consagrado al Sol a causa de su esplendor, y a Júpiter por su naturaleza templada. Puede, por tanto, templar maravillosamente el calor natural con el humor, preservar a los humores de la corrupción e infundir en los miembros y en los espíritus las virtudes propias del Sol y de Júpiter (2006: 65-66).

En el Renacimiento, por vía del neoplatonismo, sobre todo florentino, el oro va a dotarse de una dignidad metálica concreta, natural, indiscutible. Dicha dignidad, como se encarga de señalar Ficino, le viene de estar "consagrado al Sol”. El oro, para Ficino y el imaginario renacentista, "con sus rayos dorados imita al Sol”, no solo en lo puramente apariencial, sino, y ahí está la clave, en que el oro es capaz de infundir y de recoger, de simbolizar "las virtudes propias del Sol". Las virtudes propias del Sol son las virtudes propias de la luz que emite, una luz que para la filosofía neoplatónica es símbolo del bien

${ }^{9}$ Cfr. por ejemplo, aparte del propio Chastel: Hibbert (2008) o Acidini (2009). 
y la belleza divinos, instrumento con el que el astro consigue transmitir al mundo su poder vivificador, como explica el propio Ficino en el De Sole:

Con su luz y con su calor genera, hace vivir, mueve y regenera todo, y todo alegra y calienta, y manifiesta las cosas que al principio estaban ocultas, y con su movimiento determina las cuatro partes del año, y las regiones muy lejanas del Sol están igualmente alejadas de la vida (I952: 981).

León Hebreo, en un momento de sus Diálogos de amor, narra el episodio mitológico de Apolo y la transformación de la ninfa Dafne, explica que el laurel es "entre los árboles lo que es el oro entre los metales" y explica unas propiedades que pueden aplicarse perfectamente al oro:

[...] es el árbol que se atribuye al Sol y dicen que no puede alcanzarle flecha del cielo porque el tiempo no puede destruir la fama de las virtudes, ni siquiera pueden lograrlo los movimientos y las mutaciones celestes, que asaetean todas las demás cosas de este mundo inferior con vejez, corrupción y olvido (2002: I5O).

El oro se convierte así, como proponía Blecua, en el elemento que da valor al sintagma, pues representa la perfección, la vida, el tiempo pleno que no cae en el olvido. Un valor que supone una intensificación, una modulación, en el uso que del símbolo luminoso se había hecho por parte de los humanistas en sus intentos de legitimación histórica. La Edad de Oro sirve, a la vez, para apoyarse en la Antigüedad clásica que les ha servido como espejo de civilización en el que verse reflejado y para identificar esa Edad que se está trayendo con lo vivo, con lo actual, con lo que vivifica y calienta, con la mayor y más densa de las luces del neoplatonismo renacentista: la luz del Sol, que ilustra directamente al oro.

No conviene olvidar que los textos de Ficino en que se defiende y explica la dignidad del oro, así como la propia concepción de estar viviendo, de haber traído una nueva Edad de Oro, son amparados por una pujanza económica que hizo posible el desarrollo de lo que Hans Baron ha llamado el "humanismo cívico florentino" (Baron, I993), a la base del cual encontraremos la aparición de los primeros circuitos capitalistas, propiciados por las emergentes burguesías.

Resulta revelador en este sentido un pasaje de la Chronica florentina de Giovanni Villani, en el que el oro se convierte en el principal valedor, en este caso, de la dignidad y el poder de la ciudad. Se trata del pequeño episodio sobre Come di prima si feciono in Firenze i fiorini dell'oro (Villani, I99I: 279-28I). El pequeño capítulo relata la formación del florín de oro: en I252, durante el periodo de paz que siguió a las victorias de las tropas florentinas ante Piesa y Siena, "la cittade montò molto inn-istato e in ricchezze e signoria, e in gran tranquilo" (p. 280). En esa coyuntura de tranquilidad y riqueza 
[...] los banqueros de la ciudad emitieron una bella monedita de oro, estampada en su reverso con el nombre latino de la ciudad, Florentia, y en el anverso su emblema, la flor de lis. Era el famoso fiorino d'oro que llegó a ser internacionalmente conocido como la flor, la Florencia o el florín (Hibbert, 2008: I8).

Después de la descripción material de la moneda, puesta, apunta Villani, bajo la advocación de San Juan Bautista, pasa a contar una "bella novelleta", cuyas noticias le llegaron al cronista florentino gracias a un tal "Pera Balducci, discreto e savio" (Villani, I99г: 280), mercader florentino del barrio de Oltrarno.

Según la historia que narra Villani, la circulación de los florines fue tan intensa durante la época que acabaron llegando al Rey de Túnez, quien por entonces gozaba de una estrecha relación con los pisanos, enemigos declarados y antiguos de los florentinos. Los pisanos, preguntados por la ciudad que emitía dichas monedas, dieron al rey una respuesta lapidaria, llena, dice Villani, de envidia y desprecio: "Sono nostri Arabi fra terra", expresión que Villani interpreta como un "nostri montanari”, los montaraces de los pisanos, hombres rústicos, agrestes. No hay que hacer un gran esfuerzo para imaginar cómo debió sentar en el refinado ánimo florentino el desprecio pisano.

El Rey de Túnez pregunta entonces a los pisanos cuál es el nombre de su moneda de oro, cosechando solo silencio. Ante el mutismo pisano se dirige entonces a Balducci. Es el momento perfecto para el contraataque florentino. Balducci contesta "mostrando la potenzia e la magnificenzia di Fiorenza, e come Pisa a comparazione non era di potere né di gente la metà di Firenze, e che non avevano moneta d'oro, e che il fiorino era guadagnato per gli Fiorentini sopra loro per molte vittorie" (p. 28I), sumiendo así en vergüenza a la camarilla pisana.

Más allá del enfrentamiento político regional, la historia demuestra que el oro, ya en 1348 ( i tomamos la precaución de poner en una condescendiente cuarentena la veracidad de la historia), se ha convertido, a través de la moneda que los florentinos disfrutan a costa de los pisanos, en el mejor signo del esplendor florentino. Junto al demográfico, los dos argumentos que Villani esgrime con rotundidad para justificar la superioridad de Florencia sobre Pisa tienen que ver con el oro que más tarde Ficino legitimará como metal metafísicamente superior a los demás: la posesión o no de una moneda de oro, cuyo derecho al uso solo se gana después de sucesivas victorias militares.

No es de extrañar por tanto que la historiografía florentina marque con frecuencia la fecha de creación del florín como el inicio simbólico del poderío económico de la burguesía florentina que, a la postre, desembocará en el florecimiento de las artes, la pintura y la literatura. La (nueva) Edad de Oro tendría un origen simbólico y real en el propio florín de oro florentino, con lo que la etiqueta histórica deja de ser un lugar más o menos común al que acudir dentro de la tradición clásica que se está recuperando en el 
Renacimiento, para convertirse en una noción forjada a partir de unos parámetros claros y concretos para el imaginario del hombre -del hombre culto, al menos- renacentista. El concepto sirve así para legitimar a los gobernantes que están haciendo posible la vuelta al periodo de esplendor: una Edad de Oro será una edad igual en dignidad y luminosidad a dicho metal solar. Una época más perfecta, capitaneada por Lorenzo de Medici, por el papa León X, o por los propios artistas que también están contribuyendo a forjarla. Esto es, una edad capitaneada por toda una serie de personalidades que, en sintonía con el tiempo que están viviendo, se consideran a sí mismos- frente a los bárbaros, los escolásticos, los ignorantes (los medievales, en suma)- igual que ese oro que les representa y al que tratan de dotar de un significado concreto: nobles, indestructibles, ajenos a la maldad, destilados puros del Bien. 


\section{Bibliografía}

- Acidini, C. (2009). I Medici e le arti. Firenze: Giunti.

- Auerbach, E. (1975), Mímesis. México D.F.: Fondo de Cultura Económica.

- Baron, H. (1993). En busca del humanismo cívico florentino. Ensayos sobre el cambio del pensamiento medieval al moderno. México D.F.: Fondo de Cultura Económica.

- Black, R. (2006) The donation of Constantine. A new source for the concept of the Renaissance?. En Black, R. (ed.), The Renaissance: critical concepts in historical studies. Vol. I (pp. 290-32I). London: Routledge

- Blecua, A. (2006). El concepto de «Siglo de Oro». En Blecua, Alberto. Signosviejos y nuevo (pp. 31-88). Barcelona: Crítica

- Boccaccio, G. (1952). Decameron. Milano: Ricciardi.

- Boccaccio, G. (I83o), Vita di Dante Alighieri. En Dante, Rime profane e Sacre. Firenze: Leonardo Ciardetti (pp. 3-48). [Obtenido el 4 de Febrero de 2or3 desde http://books.google.es/ books?id=cIoHAAAAQAAJ\&printsec $=$ frontcover\&hl=es\# ${ }_{\mathrm{v}}=$ onepage $\& q \& \mathrm{f}=$ false $]$

- Bouwsma, W.J. (200I). Elotoño del Renacimiento (1550-1640), Barcelona: Crítica.

- Bouza, F. (2004), Prólogo. En Burckhardt, J. (2004). La cultura del Renacimiento en Italia (pp. 7-4I). Madrid: Akal.

- Burckhardt, J. (2004). La cultura del Renacimiento en Italia. Madrid: Akal.

- Burke, P. (200o). El Renacimiento europeo. Barcelona: Crítica.

- Cantimori, D. (r97i). Sulla storia dil concetto di Rinascimento. En Cantimori, D. Storici e storia (pp. 413-462). Torino: Einauidi.

- Chastel, A. (1982). Arte y humanismo en Florencia en tiempos de Lorenzo el Magnífico. Madrid: Cátedra.

- Ferguson, W. (1948). The Renaissance in historical thought : five centuries of interpretation. Cambridge: Riverside.

- Ficino, M. (1952). De Sole. En Garin, E. (ed.), Prosatori latini del quatrocento, Milano: Ricciardi, pp. 970-IOO9. 
- Ficino, M. (2006). Tres libros sobre la vida. Madrid: Asociación Española de Neuropsiquiatría.

- Garin, E. (1986). El Renacimiento italiano. Barcelona: Ariel.

- Garin, E. (I98I). La revolución cultural del Renacimiento. Barcelona: Crítica.

- Granada, M.A. (2009). El desarrollo de las concepciones de la relación entre Antigüedad, Edad Media y presente en el Renacimiento. Desde Petrarca a Giordano Bruno, INGENIUM. Revista de historia del pensamiento moderno, I, I3-29.

- Gombrich, E.H. (1984). El Renacimiento y la Edad de Oro. En Gombrich, E.H. Norma y forma. Estudios sobre el arte del Renacimiento (pp. 69-78). Madrid: Alianza.

- Hesiodo (ig64). Los trabajos y los días, La teogonía, Elescudo de Heracles. Barcelona: Iberia

- Hibbert, Christopher (2008). Florencia. Esplendor y declive de la casa de Medici, Granada: Almed.

- Kristeller, P. O. (1970). Ocho filósofos del Renacimiento italiano. México D.F.: Fondo de Cultura Económica.

- Kristeller, P.O. (1993). Elpensamiento renacentista y sus fuentes, México: Fondo de Cultura Económica.

- Lara Garrido, J. (I997). Historia y concepto (Sentido y pertinencia del marbete Siglo de Oro), en Lara Garrido, J. Del Siglo de Oro (métodos y relecciones) (pp. 23-56), Madrid: Universidad Europa de Madrid - CEES.

- León Hebreo (2002). Diálogos de amor, Madrid: Tecnos.

- Levin, H. (1972). The myth of the Golden Age in the Renaissance, Nueva York: Oxford University Press.

- Mommsen, T. (1942). Petrarch’s Conception of the 'Dark Ages', Speculum, 2, 226-242 Ovidio (1990). Metamorfosis. Madrid: CSIC.

- Panofsky, E. (1975). Renacimiento y renacimientos en el arte occidental. Madrid: Alianza.

- Petrarca, F. (1978). Obras I. Prosa. Madrid: Alfaguara.

- Petrarca, F. (200o). Carta a Dionisio da Burgo San Sepolcro. En Morrás, María (ed. y trad.) (2000), Manifiestos del humanismo (pp. 25-35). Barcelona: Península. 
- Rico, F. (1993). Elsueño del humanismo. De Erasmo a Petrarca. Madrid: Alianza.

- Rodríguez, J.C. (1990). Teoría e historia de la producción ideológica. Madrid: Akal.

- Rodríguez, J.C. (2OOI). La literatura del pobre. Granada: Comares.

- Rodríguez, J.C. (2008). Las formaciones ideológicas del barroco andaluz. En Morales, A. J. (ed.) Congreso Internacional Andalucía Barroca: actas, Iglesia de San Juan de Dios de Antequera, 17-21 de septiembre de 2007, Vol. 4, 2008 (Ciencia, filosofía y religiosidad) (pp. I6I-I70). Sevilla: Consejería de Cultura.

- Rozas, J.M. (1984). Siglo de Oro: Historia de un concepto, la acuñación del término. En AA.VV. (1984). Estudios sobre el Siglo de Oro. Homenaje al profesor Francisco Yndurain (pp. 4II-428). Madrid: Editora Nacional.

- Valla, L. (2000). Valla, Lorenzo (2000), Prólogos a las Elegancias. En Morrás, M. (ed. y trad.) (200o), Manifiestos del humanismo (pp. 75-96)). Barcelona: Península.

- Salutati, C. (I896). Epistolario (Vol. III). Roma: Istituto Storico Italiano. [Obtenido el 4 de Febrero de 2013 desde http://archive.org/stream/epistolariodicolozsalu\#page/n?/ mode/2up]

- Veronese, G. (19I5), Epistolario (Vol. II). Venecia: A spese della Società. [Obtenido el 4 de Febrero de 2013 desde http://archive.org/stream/epistolariodiguaozguar\#page/588/ mode/2up]

- Villani, Giovanni (r99i), Nuova Cronica. Parma: Fundazione Pietro Bembo/Guanda, Parma. [Obtenido el 27 de Junio de 2012 desde http://www.letteraturaitaliana.net/pdf/Volume_2/ t48.pdf]

- Virgilio (2003). Obras Completas. Madrid: Cátedra. 